\title{
Regulation of the functional structure of aquatic communities across spatial scales in a major river network
}

\author{
Eric Harvey (D) 1,2,3,4 and Florian Altermatt (iD) 1,2 \\ ${ }^{1}$ Department of Evolutionary Biology and Environmental Studies, University of Zurich, Zurich CH-8057 Switzerland \\ ${ }^{2}$ Eawag, Swiss Federal Institute of Aquatic Science and Technology, Duebendorf CH-8600 Switzerland \\ ${ }^{3}$ Département de Sciences Biologiques, Université de Montréal, Montréal H2V2S9 Canada
}

Citation: Harvey, E., and F. Altermatt. 2019. Regulation of the functional structure of aquatic communities across spatial scales in a major river network. Ecology 100(4):e02633. 10.1002/ecy.2633

Abstract. Moving beyond species count data is an essential step to better understand the effects of environmental perturbations on biodiversity and ecosystem functions, and to eventually better predict the strength and direction of those effects. Here, coupling an integrative path analysis approach with data from an extensive countrywide monitoring program, we tested the main spatial, environmental and anthropogenic drivers of change in the functional structure of aquatic macroinvertebrate communities along the entire Swiss Rhine river catchment. Functional structure was largely driven by inherent altitudinal variation influencing and cascading to regional scaled factors such as land use change and position in the riverine network, which, in turn, transformed local habitat structure variables. Those cascading effects across scales propagated through the biotic community, first affecting prey and, in turn, predators. Our results illustrate how seemingly less important local factors can act as essential transmission belts, propagating through direct and indirect pathways across scales to generate the specific context in which each functional group will strive or not, leading to characteristic landscape wide variations in functional community structure.

Key words: altitude; aquatic biodiversity; indirect effects; land use change; macroinvertebrates; meta-community; path analysis; Rhine River, Switzerland; river network; riverscape; trophic structure.

\section{INTRODUCTION}

River ecosystems constitute iconic examples of spatial complexity with complex regional scale vertical structures (from upstream to downstream; the river network) constraining organism and energy movement (Vannote et al. 1980, Rodriguez-Iturbe and Rinaldo 1997, Altermatt 2013, Abbott et al. 2018, Tonkin et al. 2018a, c), but also strong localized horizontal interactions with the terrestrial matrix influencing local habitat characteristics through changes in cross-ecosystem subsidy (Bartels et al. 2012, Richardson and Sato 2015, Little and Altermatt 2018a). The shape of river networks, which all follow the same geometric scaling properties (Rodriguez-Iturbe and Rinaldo 1997), has been shown to influence biological community dynamics and local species richness patterns (Woodward and Hildrew 2002, Muneepeerakul et al. 2008, Carrara et al. 2012, Woodward et al. 2012, Tonkin et al. 2018a, c). However, recent studies have found that the relative importance of the regional river network and local habitat characteristics is somewhat context-dependent as a function of species traits (e.g., dispersal mode) and location-specific

Manuscript received 31 October 2018; accepted 7 January 2019. Corresponding Editor: Elizabeth T. Borer.

${ }^{4}$ E-mail: eric.harvey@umontreal.ca conditions such as terrestrial land use and biotic interactions (Romanuk et al. 2006, Tonkin et al. 2016, 2018b). Although those studies tend to emphasize the importance of considering both local and regional factors to understand variations in aquatic community, total explanatory power remains generally low (Heino et al. 2015).

In part, the explanatory power issue might be caused by current approaches tending to focus on the relative importance of regional vs. local factors to identify the dominant drivers while largely ignoring the inherent structure of interdependences among regional and local factors (Cottenie et al. 2003, Cottenie 2005, Göthe et al. 2013, Kuglerová et al. 2014, Borthagaray et al. 2015, Heino et al. 2015, Mayfield and Stouffer 2017). The often-assumed dichotomy between regional and local factors generally erodes when considering the mechanisms behind those effects (Kuglerová et al. 2014, Masahiro et al. 2018). For instance, many regional factors, such as altitude, do not have direct mechanistic effects on community structure, but rather their effect is indirect via influences on local factors that, in turn, will causally impact communities. Other regional factors such as land use cover are likely to have both direct (e.g., changes in habitat structure) and indirect (e.g., changes in water chemical quality) impacts on aquatic communities. Thus, local factors that may seem less important at 
first might effectively act as transmission belts, propagating a part or the total effects of some regional factors on local community structure. Those effects are then likely to propagate within biological communities as a function of biotic interactions (e.g., effects on prey, which, in turn, affect predators). Overall, we cannot rely on whole-community endpoint biodiversity measurements only, such as local species richness, to understand the direct and indirect pathways by which regional and local factors interact and propagate through biological communities to influence their structure and function (Jackson et al. 2016, Cernansky 2017, Hillebrand et al. 2017). While this is widely acknowledged (Tonkin et al. 2018c), studies on riverine metacommunities still mostly focus on species-richness as a descriptor of local communities (Altermatt 2013, Heino et al. 2015), and ignore ecologically more relevant descriptors, such as the functional structure and the relative abundance of functionally different trophic groups.

Here, we disentangled the main spatial, environmental, and anthropogenic drivers shaping stream macroinvertebrate functional structure across an entire river catchment. Starting from abundance data from a Swisswide biodiversity-monitoring program we collected functional traits on each taxon to reconstruct the functional structure of each local community for 364 sites covering the entire Swiss Rhine river catchment. We used functional groups rather than taxa for three main complementary reasons. (1) Theoretical and empirical evidences suggest that the regional context tends to affect some functional groups more than others, either based on trophic dependencies (Gravel et al. 2011, Harvey and MacDougall 2014) or dispersal capacity (Tonkin et al. 2018a). Thus, the use of functional groups is not only biologically more meaningful but should also improve on the general issue of low explanatory powers described above, because the response to regional and local effects will be better defined for each functional group (e.g., all taxa within a functional group share the same resources). (2) The use of functional groups is an efficient way to bridge from community- to ecosystemlevel effects, because clearly defined functions can be associated with different groups, such as predators, decomposers, or parasites, which could ultimately be linked with ecosystem processes. (3) Finally, all streams do not necessarily share the same taxa, but they do share the same general functional components (Vannote et al. 1980), thus allowing generalization and larger inference of results outside the specific study system.

Integrating data related to land use change, local water chemical and physical properties, regional factors related to altitude and position along the dendritic network, we used an integrative path analysis framework to identify specific pathways by which factors interact across spatial scales to affect the functional structure of stream invertebrate communities. We started from a meta-model representing our initial predictions of the direct and indirect effects of each predictor on each functional group (Appendix S1: Fig. S1). The metamodel was built based on a priori knowledge about the system (Altermatt 2013, Altermatt et al. 2013, Kaelin and Altermatt 2016, Masahiro et al. 2018), and also based and facilitated by the use of functional groups defined by their main feeding resources (e.g., any factor affecting a given resource will predictably affect each taxon within a specific functional group, see Appendix S1: Fig. S1). The SEM approach allowed us to disentangle the specific pathways linking correlated predictors (i.e., either in the graphical form of a fork, mediator or collider) and their relative importance. As opposed to many previous studies (Cottenie 2005, Altermatt 2013, Heino et al. 2015, Tonkin et al. 2016), interactions between local and regional factors in our study represent "causal" chains of indirect effects testing directly the "propagation" of effects "across scales" in a hierarchical sense.

\section{Methods}

\section{Data}

Our study used the aquatic macroinvertebrate abundance data from 364 sites across the whole Rhine river catchment in Switzerland, covering about $30,000 \mathrm{~km}^{2}$. The data are collected and curated by a Swiss governmental monitoring program ("Biodiversity Monitoring in Switzerland BDM"; BDM Coordination Office 2014). Sampling is done following a systematic sampling grid and was conducted in wadeable streams, second order or larger in size, thus excluding standing waterbodies, firstorder streams, and large rivers inaccessible by wading (Stucki 2010). Each site was sampled once between 2009 and 2014 with seasonal timing of sampling adjusted with respect to elevation: the sampling period for a site was based on local phenology so as to collect as many macroinvertebrate taxa as possible for a given elevation (Stucki 2010). Because the yearly subsets of sites were randomly sampled across the catchment, variations in annual climatic conditions are not expected to affect community composition in a systematic direction. We also validated this by including the number of years of sampling as a factor in our models; it was never identified as a significant/relevant covariable and thus could be ignored and data were pooled across years.

The survey was done using a standard kick-net $(25 \times 25 \mathrm{~cm}, 500 \mu \mathrm{m}$ mesh) sampling procedure defined in the Swiss Macrozoobenthos Level I module for stream benthic macroinvertebrates (BDM Coordination Office; see Stucki 2010, Altermatt et al. 2013). Briefly, a total of eight kick-net samples were taken at each site to cover all major microhabitats within a predefined section of the river (area covered per site was width $\times 10$ times the average width in length; subsamples were pooled). Therefore, all locally represented habitat types (including various sediment types such as rocks, pebbles, sand, mud, submerged roots, macrophytes, leaf litter, and 
artificial river-beds) and water velocities were sampled. Samples were preserved in $80 \%$ ethanol and returned to the laboratory for processing. In the laboratory, all macroinvertebrates used in this study were sorted and identified to the family level by trained taxonomists (total of 63 families see Appendix S1: Table S1 for a list). For further details on the sampling method and the database (see also Altermatt et al. 2013, Seymour et al. 2016, Kaelin and Altermatt 2016).

\section{Predictors}

We used 38 predictors representative of regional, local and hydrological conditions, as well as land use coverage and position in the dendritic network (see Appendix S1: Table S2 for a complete list of each variable with description). Regional predictors included altitude at the sampling site and catchment size. Local predictors represent instream habitat conditions that were measured directly at sampling site. Local predictors included features of channel cross-section (e.g., width, depth, and their variability), riverbed conditions (e.g., mud deposition and attached algae), aquatic conditions (e.g., turbidity and dissolved iron sulfide concentration), and a discrete ranking of human alterations to riverbank and riverbed (see Stucki [2010] for details). Hydrological predictors are factors representing geometry conditions of the river network in the upstream catchment of a sampling site. Those predictors included geomorphological (e.g., riverbed slope), hydrological (e.g., mean discharge) and chemical (e.g., inflowing wastewater volume) conditions. Land use predictors represent terrestrial conditions surrounding a sampling site. Those predictors included six land use classes considering adjacent influences to the local site with a lateral buffer distance of $500 \mathrm{~m}, 1,5,10$, 100 , or $1,000 \mathrm{~km}$ (Seymour et al. 2016). We know from previous work on this data that the $5-\mathrm{km}$ scale is most significant in affecting stream invertebrate diversity (Masahiro et al. 2018); thus, we used only the six land use classes with lateral buffer distance of $5 \mathrm{~km}$ in our analyses. Network predictors were measured using a directed graph and represent the position of each sampling site in the river dendritic network (e.g., centrality and distance to the outlet). Centrality was measured as the out-closeness centrality, which measures how many steps are required, from a focal vertex, to access every other vertex in the directed network (Csardi and Nepusz 2006).

Many land use predictors were strongly skewed toward zero leading to important loss of information and degrees of freedom when analyzing each variable individually. Instead, to emphasize a more continuous transition between each land use type, for further analysis, we used first axis scores from a canonical correspondence analysis representing a gradual shift in land use from high proportion of human settlement and agricultural lands to high proportion of natural meadows (see Appendix S1: Fig. S2). Such a gradient is dominant in
Switzerland with lowlands representing most of the urban and agricultural lands. Grouping our land use data this way reduced our total number of predictors to 34 for 364 sites.

\section{Functional structure}

We built the functional structure of each stream macroinvertebrate community for each site, using the freshwaterecology European database (Schmidt-Kloiber and Hering 2015) and extracting the feeding type metric (sensu Moog 1995) for each of our 63 stream macroinvertebrate families. The data from the freshwaterecology database were at the species level. Thus, we used averaged values across all species within family to determine the dominant feeding type of each of the 63 families. At the end, our data were comprised of abundance data for 63 families across seven feeding groups (following definition by Moog [1995], see Appendix S1: Table S1) defining overall functional structure. The seven groups were grazer scrapers (13 families, mainly feeding on particulate organic matter from endolithic and epilithic algal tissues and biofilm), shredders (10 families, mainly feeding on coarse particulate organic matter from fallen leaves and plant tissue), gatherer collectors (10 families, mainly feeding on sedimented fine particulate organic matter), active filter feeders (one family, mainly feeding on suspended particulate organic matter actively filtered from the water column), passive filter feeders (two families, mainly feeding on suspended particulate organic matter passively trapped from running water), predators (24 families, mainly feeding on prey), and parasites (two families, mainly feeding from hosts).

\section{Analyses}

Ordination.-To identify the main environmental and spatial drivers of the functional structure of stream macroinvertebrate communities, we used a distancebased redundancy analysis on Euclidean distances (db-RDA, following Legendre and Anderson [1999]) followed by an automatic stepwise model building approach for constrained ordination based on the adjusted $R^{2}$ of the full model (499 permutations, following Blanchet et al. [2008]). The significance level at $P<0.05$ of the final model and of each selected term was tested using a permutation ANOVA (200 permutations, see Table 1). The uses of pairwise Euclidean distances ensure that our analyses really emphasize changes in the relative proportion of each functional group within each community rather than between site changes in absolute abundance or composition (Anderson et al. 2011). Because we did not have any a priori knowledge on which predictors might be most important, we used all 34 predictors into our analytical pipeline. At the end, eight predictors were selected with first and second axes respectively explaining $67 \%$ and $18 \%$ of the total variance for the constrained axes. 
Structural equation model.-Ordination approaches provide insightful information on main drivers; however, they do not provide information on the potential interactions and pathways by which each driver affects different functional groups. For instance, a regional factor such as altitude does not have any direct ecological relevance. Rather, altitude will affect functional groups via its effects on local factors (e.g., temperature or deciduous forest cover). Thus, even variables that may seem less important at first might act as transmission belts for the effects of other factors on stream invertebrate functional structure. Moreover, factors affecting predators can do so by affecting the predator directly (e.g., high turbidity decreasing hunting efficiency) or indirectly by affecting

TABle 1. Permutation ANOVA (200 permutations) on the final db-RDA model.

\begin{tabular}{lrrrc}
\hline \hline & df & \multicolumn{1}{c}{ SS } & \multicolumn{1}{c}{$F$} & $P$ \\
\hline Altitude & 1 & 3.63 & 22.75 & 0.001 \\
Human modification indices & 3 & 2.16 & 4.51 & 0.001 \\
Foam level & 2 & 0.97 & 3.04 & 0.006 \\
Mud level & 2 & 0.88 & 2.75 & 0.004 \\
Land use gradient & 1 & 0.81 & 5.10 & 0.001 \\
Depth variation & 2 & 0.95 & 2.98 & 0.012 \\
Deciduous cover & 1 & 0.60 & 3.80 & 0.011 \\
Turbidity level & 2 & 0.72 & 2.27 & 0.031 \\
Residual & 193 & 30.86 & & \\
\hline
\end{tabular}

its prey. Based on the information from the db-RDA analysis, we built a meta-model representing the potential links of importance in the system and how they affect functional structure. We hypothesized that effects would mainly cascade from regional factors affecting local factors, which in turn, affect different functional groups (Fig. 1a). For this exercise, variables were classified as either regional or local based on the inherent hierarchy in their effects. Local scale variables are variables measured at the local scale and that directly influenced biological processes. Regional scale variables are features of the landscape and that can indirectly influence biological processes through their effects on lowerlevel variables. This classification is more like a gradient than a bimodal (regional vs. local) classification and allowed us to properly represent the hierarchical nature of the predictors across scales. We then used structural equation modeling to test the fit of this initial metamodel against the data. Subsequently, we used the residual covariance matrix and modification indices (Rosseel 2012) to identify potentially important missing links that were not included in the original meta-model. After adding those links to the model, we then identified and pruned least important links (based on $P$ values and effect on model fit) to avoid over-parameterization and over estimation of explanatory power. Because we used categorical factors, we measured the fit of our model to the data with a robust diagonally weighted least square estimator (DWLS; see Rosseel 2012). Our final model

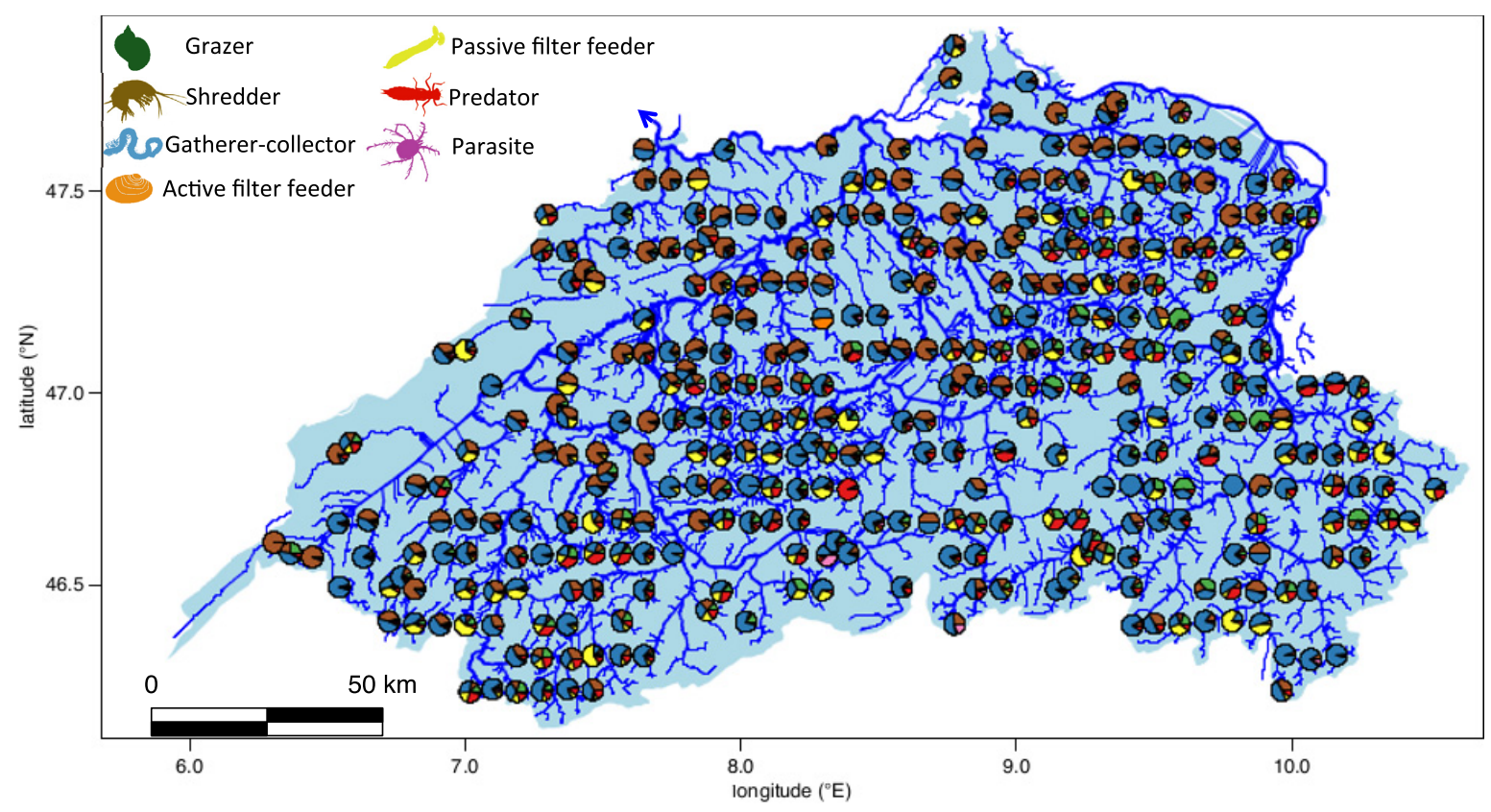

FIG. 1. Spatial variation in the functional structure of riverine macroinvertebrate communities. The figure shows the Rhine river basin. All third-order streams or larger are shown (arrow indicates direction of flows). Each pie chart represents the functional structure (relative abundance of each functional group in the community) for one of the 364 sampling sites across the river basin. Each functional group is represented by a silhouette of one of its iconic taxon: gatherer-collector (Oligochaeta), grazer-scraper (Limnaeidae), predator (Cordulegaster), passive filter feeder (Simuliidae), active filter feeder (Sphaeridae), parasite (Hydracaria), shredder (Gammaridae). 
converged after 105 iterations and showed a good fit to the data $(n=364$, DWLS $=63.36$, df $=62, P=0.428)$.

All analyses were conducted with $\mathrm{R}$ 3.1.2 (R Core Team 2016), using the vegan package (Oksanen et al. 2015) for the db-RDA (capscale function) and stepwise model building (ordistep function), the igraph package (Csardi and Nepusz 2006) to compute network metrics, and the lavaan package (Rosseel 2012) for SEM analysis. The code to reproduce analysis and results is available at https://zenodo.org/badge/83574106.svg

\section{RESUlTS}

Testing the main spatial, environmental, and anthropogenic drivers of the functional structure of aquatic macroinvertebrate communities along the Swiss Rhine river catchment, we found that variations in relative (Figs. 1, 2) and absolute (Fig. 3) abundances of each functional group across the whole river basin were largely driven by altitudinal variations (Table 1 and Fig. 2). In turn, altitude influenced several other regional and local scale factors leading to a complex array of direct and indirect pathways across spatial scales, eventually leading to landscape wide variations in functional community structure (Figs. 1, 3).
More specifically, altitude led to a decline in deciduous forest cover, was associated with an increase in distance to river outlet and drove land use change from high settlement and agricultural lands to high altitudinal natural meadows (Fig. 3). In turn, those regional factors influenced local habitats with transition to natural meadows leading to lower water foam levels (a proxy of eutrophication), and increased distance to outlet leading to higher turbidity level (Fig. 3). Lowland upstream sites were associated with higher probability of finding modified streams (see negative effects of altitude and positive effects of distance to outlet on river modification index on Fig. 3). Local habitat factors then affected various functional groups with mud-level negatively impacting shredder, passive filter feeder and grazer-scraper abundances (Fig. 3), foam (proxy of eutrophication) positively impacting gatherer-collector and passive filter feeder, river habitat modification positively influencing grazer-scraper, gatherer-collector and parasite, and higher riverbed variations in depth positively affecting passive filter feeder (Fig. 3). Finally, all those regional and local factors affected predator abundance through affecting their prey (Fig. 3).

We also found evidence for direct effects of regional factors on some functional groups. Altitude had a direct

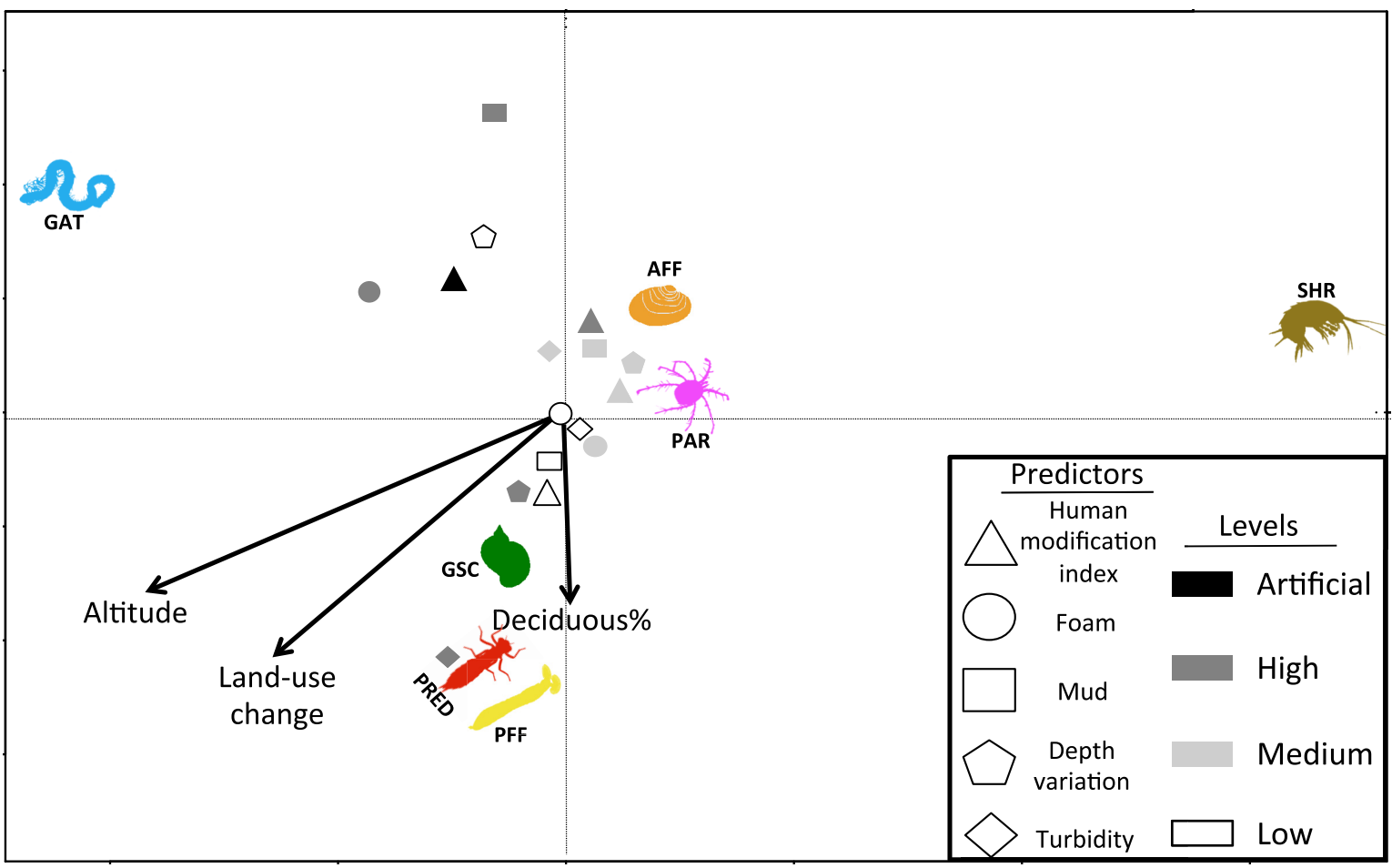

FIG. 2. Main environmental and spatial drivers of the functional structure of riverine macroinvertebrate communities. The ordination figure is the final distance-based redundancy analysis (db-RDA) model selected by an automatic stepwise model building approach based on adjusted $R^{2}$. The first and second axes respectively explain $67 \%$ and $18 \%$ of the total variation in functional structure (relative abundance of each functional group per community, see Methods). A specific geometric shape represents each categorical predictor, with the gray gradient representing the level of each predictor. For the explanation of the silhouette of each functional group and their abbreviations, see Fig. 1. 
A)

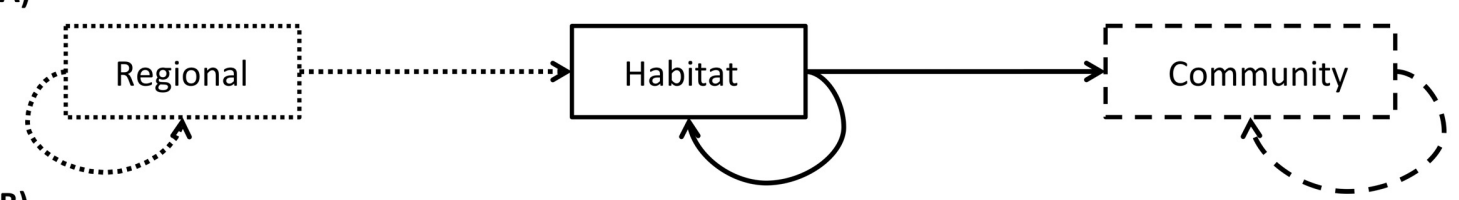

B)

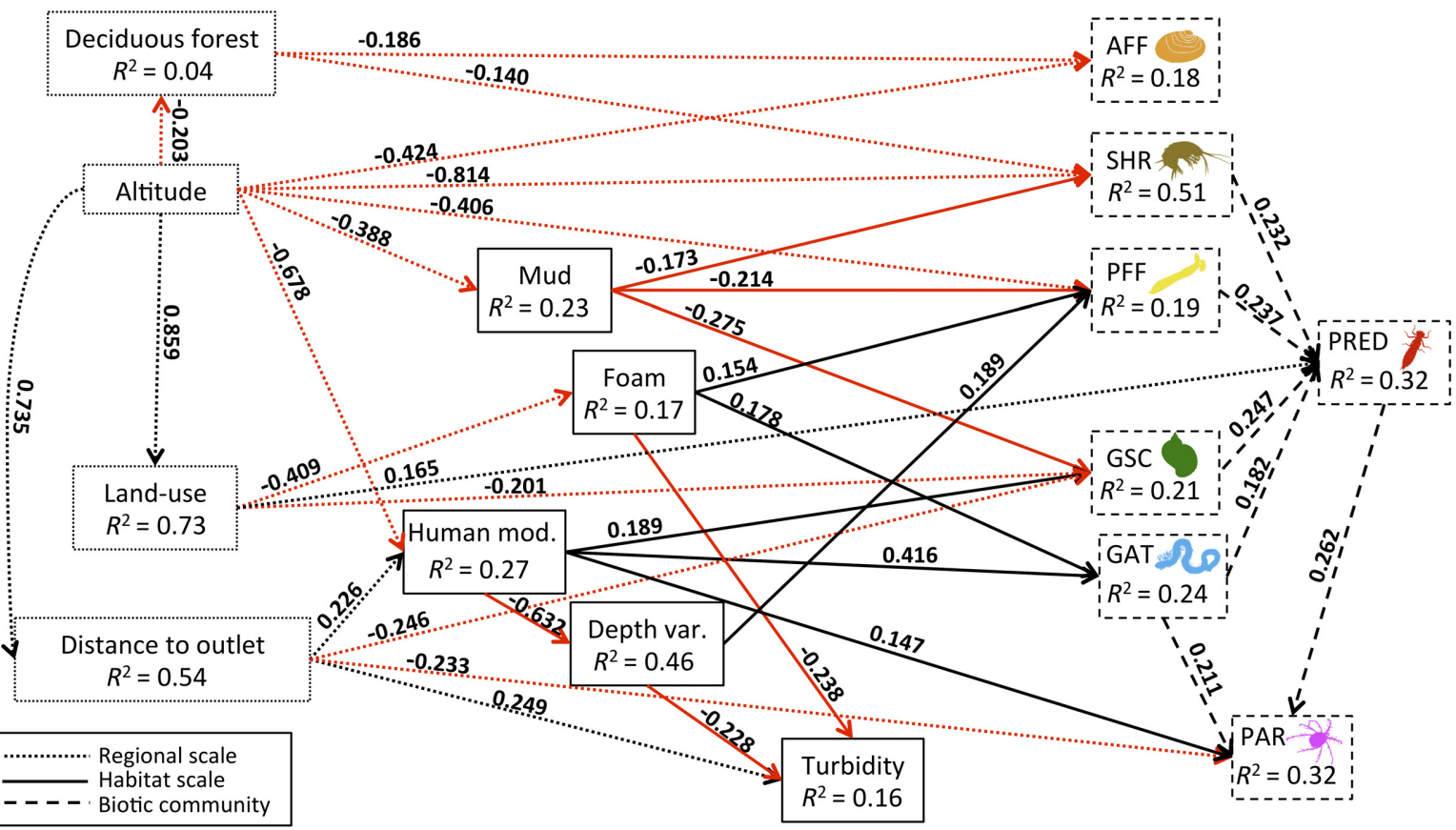

FIG. 3. Direct and indirect pathways by which regional and local drivers influences riverine macroinvertebrate functional structure. (A) We hypothesized that most regional (dotted lines) factors would influence the biotic community (dashed lines) indirectly via an effect on local habitat factors (solid lines). We also expected within spatial scale interaction structure at both regional and local scales (looped arrows). Changes to biotic communities are usually analysed assuming that each predictor influence each taxa or functional group independently in the community; however, we hypothesized that the specific structure of interactions within a biotic community would rather drive the propagation of effects from specific entry points (prey) to the entire community (looped arrow on the community box). (B) Final structural equation model illustrating the different direct and indirect pathways by which regional (dotted lines) and local (solid line) factors interact and then propagate through the functional community (dashed lines). Each value is the standardized coefficient (standardized estimate from each partial regression, all significant at $P<0.05$ ), representing the strength of the effect of one variable on another. Red arrows, negative effects; black arrows, positive effects. Each functional group is represented by a silhouette of one of its iconic taxon: GAT, gatherer-collector (Oligochaeta); GSC, grazer-scraper (Limnaeidae); PRED, predator (Cordulegaster); PFF, passive filter feeder (Simuliidae); AFF, active filter feeder (Sphaeridae); PAR, parasite (Hydracaria); SHR, shredder (Gammaridae).

negative impact on passive filter feeder and shredder abundances (Fig. 3), potentially mediated by unmeasured (i.e., missing) local variables. Land use transition to natural meadows had a direct positive effect on predator abundance suggesting that predators tend to fare better in high altitudinal streams surrounded by natural meadows than in low altitude zones characterized by a matrix of agricultural lands and human settlements, and a negative effect on grazer-scraper (Fig. 3). Distance to outlet directly influenced gatherer-collector and parasite abundances negatively (Fig. 3), illustrating that location along the river network has both indirect (mediated by local habitat factors) and direct effects on aquatic invertebrate functional structure.
There were also causal pathways among variables at each spatial scale as described above for altitude and regional factors. Among local factors, river modifications negatively impacted stream depth variation, which in turn, negatively influenced turbidity (Fig. 3). Thus, river modifications had an indirect positive effects on turbidity mediated by a change in riverbed depth variation.

Overall, our results illustrate the complex interactions among local and regional scale predictors in shaping functional structure along an entire catchment (Fig. 3) and how the outcome of those interactions across scale generates the specific context in which each functional group will strive or not, leading to large spatial scale variations in functional community structure (Figs. 1,2). 


\section{DisCUSSION}

It is increasingly acknowledged that local species richness, still probably the most commonly used descriptor of ecological communities, may not be an adequate proxy beyond a pure biodiversity perspective, and be especially limited for understanding the ecosystem processes and dynamics of natural communities (Harvey et al. 2016, Hillebrand et al. 2017). Consequently, describing communities from the perspective of species traits, functional roles, or interactions may be more rewarding to understand and eventually to conserve the integrity of ecological communities (McGill et al. 2006, Hillebrand and Matthiessen 2009, Tylianakis et al. 2010, Harvey et al. 2016).

Riverine ecosystems offer a prime case example in which the study of both drivers as well as responses of the functional structure of communities may be very insightful. Rivers are among the most biodiverse ecosystems worldwide with respect to species richness (Dudgeon et al. 2006), but this diversity is often not attributable to environmental factors (Heino et al. 2015). In contrast, however, the functional role of major species groups in these systems, such as macroinvertebrates, is well described, with species covering functions from decomposers, to predators and parasites, and the functional role of these species is also linked to major processes and functions at the ecosystem level (Little and Altermatt $2018 b$ ). Thus, including and analyzing the drivers of the functional structure of aquatic macroinvertebrate communities may not only give a better understanding of biodiversity, but also of associated ecosystem functions.

Testing for the main environmental and spatial drivers of functional structure in stream macroinvertebrates, we found a complex array of direct and indirect pathways by which regional and local drivers interact to influence relative and absolute abundances of aquatic macroinvertebrate functional groups, eventually leading to landscape wide variations in functional community structure across a major river network. More specifically, cascading effects across spatial scales starting with altitude as a key driver influencing other regional factors, which in turn affected various local habitat characteristics directly to influence functional group abundances. Most effects propagated through the community by first affecting prey, which then affected predator abundances.

The importance of the river network has been shown to be context-dependent as a function of location-specific conditions such as terrestrial land use and biotic interactions (Tonkin et al. 2016). Our results suggest that those location-specific conditions can, in part, interact with some river network properties because they are not distributed randomly along the network but rather located at specific substructures in the network. Those effects constitute in themselves indirect effects of the river network rather than the absence of effect. More specifically, we showed that distance to outlet affected functional groups directly but also indirectly via its positive effect on the human modification index. A main component of this result is the observation that lowland headwater locations are systematically more affected by human-induced riverbed and riverbank modifications than headwaters at higher elevations. Consequently, our results illustrate how the significance of spatial and regional factors can be masked by location-specific conditions when indirect pathways are not being taken into account (Grace et al. 2016).

Our results also emphasize the complex response of each individual functional group (see Fig. 3) to each individual environmental and spatial factor. Interpreting any of these patterns independently can be misleading and only an integrative approach allows a coherent understanding of community structure, and eventually predicting shifts in response to environmental changes (Peterson et al. 2014, Grace et al. 2016, Masahiro et al. 2018). Although our predictors are hierarchically organized (e.g., regional factors influencing local factors influencing prey, which in turn impact predators) rather than multiplicative, our study echoes recent calls to take a more integrative approach to the study of multiplestressors and environmental changes, especially in aquatic ecosystems (Ormerod et al. 2010, Elbrecht et al. 2016, Jackson et al. 2016, Beermann et al. 2018).

Shifts in functional structure are a well-known driver of ecosystem processes (Emmett Duffy et al. 2005, Harvey et al. 2013, Poisot et al. 2013, Trzcinski et al. 2016). Predicting those shifts, however, is a challenging endeavor because of multiple stressors interacting at different spatial scales and potentially affecting different functional groups simultaneously. By breaking down the many indirect pathways by which main effects (e.g., altitude or land use change) are affecting functional groups, it is much easier to understand the direction of effects. For instance, shredders feed on dead plant material and thus any factors reducing the amount (altitude) or access (mud) to that resource will impact their abundances and, in turn, a reduction in the relative importance of shredders can be directly taken as evidence of ecosystem-level changes (see next paragraph). In that context, predicting the response and the effect of environmental changes becomes a lot less challenging. We observed important shifts in functional group's relative abundances. For instance, our ordination analysis identified an important gradient from gatherer-collector-dominated to shredderdominated communities (Figs. 1, 2). This is corroborated by the structural equation modeling where higher gatherer-collector abundance is mainly associated with high levels of riverbed and bank modifications, while shredders seem to strive in less disturbed environments (Figs. 2, 3).

At the ecosystem level, we postulate that this shift from coarse (shredder) to fine particle (gatherer-collector) feeders along those environmental gradients is linked to variations in the type of resource available (Lepori and Malmqvist 2007). Such shifts in functional structures have also implications for energy transfer and 
stoichiometric constraints in the community because shredders mainly feed on allochthonous leaf particles, which tend to be rich in carbon but nitrogen poor, while fine particles associated to agricultural lands tend to be nutrient rich but a poorer source of carbon.

Looking at the functional or trophic structure of communities is an essential step to better understand the effects of environmental perturbations on biodiversity and ecosystem functions, but also to eventually better predict the strength and direction of those effects (Harvey et al. 2016, Cernansky 2017, Hillebrand et al. 2017). Our results illustrate the complex interactions among local and regional scale predictors in driving functional structure and how the outcome of those interactions across scale generates the observed large-scale variations in aquatic functional community structure.

\section{ACKNOWLEDGMENTS}

The Swiss Federal Office for the Environment (BAFU) provided the BDM data. We thank Roman Alther for discussion and for help in extracting GIS data. We thank the many people who conducted field and laboratory work within the biodiversity monitoring program, and Nicolas Martinez and Tobias Roth for help in data provisioning. Funding was provided by the Swiss National Science Foundation Grants PP00P3_150698 and PP00P3_179089 and the University of Zurich Priority Program (URPP) on Global Change and Biodiversity to F. Altermatt and by the University of Zurich Forschungskredit to E. Harvey. E. Harvey and F. Altermatt designed the research; F. Altermatt provided and prepared the data; E. Harvey processed and analysed the data; E. Harvey wrote the first draft of the manuscript; E. Harvey and F. Altermatt contributed for further manuscript revisions.

\section{Literature Cited}

Abbott, B. W., et al. 2018. Unexpected spatial stability of water chemistry in headwater stream networks. Ecology Letters 21:296-308.

Altermatt, F. 2013. Diversity in riverine metacommunities: a network perspective. Aquatic Ecology 47:365-377.

Altermatt, F., M. Seymour, and N. Martinez. 2013. River network properties shape $\alpha$-diversity and community similarity patterns of aquatic insect communities across major drainage basins. Journal of Biogeography 40:2249-2260.

Anderson, M. J., et al. 2011. Navigating the multiple meanings of $\beta$ diversity: a roadmap for the practicing ecologist. Ecology Letters 14:19-28.

Bartels, P., J. Cucherousset, K. Steger, P. Eklöv, L. J. Tranvik, and H. Hillebrand. 2012. Reciprocal subsidies between freshwater and terrestrial ecosystems structure consumer resource dynamics. Ecology 93:1173-1182.

BDM Coordination Office. 2014. Swiss Biodiversity Monitoring BDM. Description of Methods and Indicators. Federal Office for the Environment, Bern. Environmental studies no. 1410. 103 pp.

Beermann, A. J., V. Elbrecht, S. Karnatz, L. Ma, C. D. Matthaei, J. J. Piggott, and F. Leese. 2018. Multiple-stressor effects on stream macroinvertebrate communities: a mesocosm experiment manipulating salinity, fine sediment and flow velocity. Science of the Total Environment 610-611:961-971.

Blanchet, F. G., P. Legendre, and D. Borcard. 2008. Forward selection of explanatory variables. Ecology 89:2623-2632.
Borthagaray, A. I., M. Berazategui, and M. Arim. 2015. Disentangling the effects of local and regional processes on biodiversity patterns through taxon-contingent metacommunity network analysis. Oikos 124:1383-1390.

Carrara, F., F. Altermatt, I. Rodriguez-Iturbe, and A. Rinaldo. 2012. Dendritic connectivity controls biodiversity patterns in experimental metacommunities. Proceedings of the National Academy of Sciences USA 109:5761-5766.

Cernansky, R. 2017. Biodiversity moves beyond counting species. Nature News 546:22.

Cottenie, K. 2005. Integrating environmental and spatial processes in ecological community dynamics. Ecology Letters 8:1175-1182.

Cottenie, K., E. Michels, N. Nuytten, and L. D. Meester. 2003. Zooplankton metacommunity structure: regional vs. local processes in highly interconnected ponds. Ecology 84:9911000.

Csardi, G., and T. Nepusz. 2006. The igraph software package for complex network research. InterJournal Complex Systems 1695.

Dudgeon, D., et al. 2006. Freshwater biodiversity: importance, threats, status and conservation challenges. Biological Reviews 81:163-182.

Elbrecht, V., A. J. Beermann, G. Goessler, J. Neumann, R. Tollrian, R. Wagner, A. Wlecklik, J. J. Piggott, C. D. Matthaei, and F. Leese. 2016. Multiple-stressor effects on stream invertebrates: a mesocosm experiment manipulating nutrients, fine sediment and flow velocity. Freshwater Biology 61:362-375.

Emmett Duffy, J., J. Paul Richardson, and K. E. France. 2005. Ecosystem consequences of diversity depend on food chain length in estuarine vegetation. Ecology Letters 8:301-309.

Göthe, E., D. G. Angeler, and L. Sandin. 2013. Metacommunity structure in a small boreal stream network. Journal of Animal Ecology 82:449-458.

Grace, J. B., et al. 2016. Integrative modelling reveals mechanisms linking productivity and plant species richness. Nature 529:390-393.

Gravel, D., F. Massol, E. Canard, D. Mouillot, and N. Mouquet. 2011. Trophic theory of island biogeography. Ecology Letters 14:1010-1016.

Harvey, E., and A. S. MacDougall. 2014. Trophic island biogeography drives spatial divergence of community establishment. Ecology 95:2870-2878.

Harvey, E., A. Séguin, C. Nozais, P. Archambault, and D. Gravel. 2013. Identity effects dominate the impacts of multiple species extinctions on the functioning of complex food webs. Ecology 94:169-179.

Harvey, E., I. Gounand, C. L. Ward, and F. Altermatt. 2016. Bridging ecology and conservation: from ecological networks to ecosystem function. Journal of Applied Ecology 54:371379.

Heino, J., et al. 2015. A comparative analysis reveals weak relationships between ecological factors and beta diversity of stream insect metacommunities at two spatial levels. Ecology and Evolution 5:1235-1248.

Hillebrand, H., and B. Matthiessen. 2009. Biodiversity in a complex world : consolidation and progress in functional biodiversity research. Ecology Letters 00:1405-1419.

Hillebrand, H., et al. 2017. Biodiversity change is uncoupled from species richness trends: consequences for conservation and monitoring. Journal of Applied Ecology 55:169-184.

Jackson, M. C., C. J. G. Loewen, R. D. Vinebrooke, and C. T. Chimimba. 2016. Net effects of multiple stressors in freshwater ecosystems: a meta-analysis. Global Change Biology 22:180-189.

Kaelin, K., and F. Altermatt. 2016. Landscape-level predictions of diversity in river networks reveal opposing patterns for 
different groups of macroinvertebrates. Aquatic Ecology 50:283-295.

Kuglerová, L., R. Jansson, R. A. Sponseller, H. Laudon, and B. Malm-Renöfält. 2014. Local and regional processes determine plant species richness in a river-network metacommunity. Ecology 96:381-391.

Legendre, P., and M. J. Anderson. 1999. Distance-based redundancy analysis: testing multispecies responses in multifactorial ecological experiments. Ecological Monographs 69:1-24.

Lepori, F., and B. Malmqvist. 2007. Predictable changes in trophic community structure along a spatial disturbance gradient in streams. Freshwater Biology 52:2184-2195.

Little, C. J., and F. Altermatt. 2018a. Landscape configuration alters spatial arrangement of terrestrial-aquatic subsidies in headwater streams. Landscape Ecology 33:1-13.

Little, C. J., and F. Altermatt. 2018b. Species turnover and invasion of dominant freshwater invertebrates alter biodiversityecosystem-function relationship. Ecological Monographs 88:461-480.

Masahiro, R., E. Harvey, C. T. Robinson, and F. Altermatt. 2018. Nonlinear higher order abiotic interactions explain riverine biodiversity. Journal of Biogeography 45:628-639.

Mayfield, M. M., and D. B. Stouffer. 2017. Higher-order interactions capture unexplained complexity in diverse communities. Nature Ecology \& Evolution 1:0062.

McGill, B. J., B. J. Enquist, E. Weiher, and M. Westoby. 2006. Rebuilding community ecology from functional traits. Trends in Ecology \& Evolution 21:178-185.

Moog, O. 1995. Fauna Aquatica Austriaca. Bundes ministerium fur Land- und Fortswirtschaft, Vienna, Austria.

Muneepeerakul, R., E. Bertuzzo, H. J. Lynch, W. F. Fagan, A. Rinaldo, and I. Rodriguez-Iturbe. 2008. Neutral metacommunity models predict fish diversity patterns in MississippiMissouri basin. Nature 453:220-222.

Oksanen, J., et al. 2015. vegan: Community Ecology Package. https://CRAN.R-project.org/package=vegan

Ormerod, S. J., M. Dobson, A. G. Hildrew, and C. R. Townsend. 2010. Multiple stressors in freshwater ecosystems. Freshwater Biology 55:1-4.

Peterson, R. O., J. A. Vucetich, J. M. Bump, and D. W. Smith. 2014. Trophic cascades in a multicausal world: Isle Royale and Yellowstone. Annual Review of Ecology, Evolution, and Systematics 45:325-345.

Poisot, T., N. Mouquet, and D. Gravel. 2013. Trophic complementarity drives the biodiversity-ecosystem functioning relationship in food webs. Ecology Letters 16:853-861.

R Core Team. 2016. R: A language and environment for statistical computing. R Foundation for Statistical Computing, Vienna, Austria. URL https://www.R-project.org/

Richardson, J. S., and T. Sato. 2015. Resource subsidy flows across freshwater-terrestrial boundaries and influence on processes linking adjacent ecosystems. Ecohydrology 8:406-415.
Rodriguez-Iturbe, I., and A. Rinaldo. 1997. Fractal river basins: chance and self-organization. Cambridge University Press, New York, New York, USA.

Romanuk, T. N., L. J. Jackson, J. R. Post, E. McCauley, and N. D. Martinez. 2006. The structure of food webs along river networks. Ecography 29:3-10.

Rosseel, Y. 2012. lavaan: an R package for structural equation modeling. Journal of Statistical Software 48:1-36.

Schmidt-Kloiber, A., and D. Hering. 2015. www.freshwaterecol ogy.info-An online tool that unifies, standardises and codifies more than 20,000 European freshwater organisms and their ecological preferences. Ecological Indicators 53: 271-282.

Seymour, M., K. Deiner, and F. Altermatt. 2016. Scale and scope matter when explaining varying patterns of community diversity in riverine metacommunities. Basic and Applied Ecology 17:134-144.

Stucki, P. 2010. Méthodes d'analyse et d'appreciation des cours d'eau en Suisse. Macrozoobenthos-niveau R. Page 61. Office federal de l'environnement, Berne, Suisse.

Tonkin, J. D., J. Heino, A. Sundermann, P. Haase, and S. C. Jähnig. 2016. Context dependency in biodiversity patterns of central German stream metacommunities. Freshwater Biology 61:607-620.

Tonkin, J. D., F. Altermatt, D. S. Finn, J. Heino, J. D. Olden, S. U. Pauls, and D. A. Lytle. 2018a. The role of dispersal in river network metacommunities: patterns, processes, and pathways. Freshwater Biology 63:141-163.

Tonkin, J. D., J. Heino, and F. Altermatt. 2018b. Metacommunities in river networks: the importance of network structure and connectivity on patterns and processes. Freshwater Biology $63: 1-5$

Tonkin, J. D., D. M. Merritt, J. D. Olden, L. V. Reynolds, and D. A. Lytle. 2018c. Flow regime alteration degrades ecological networks in riparian ecosystems. Nature Ecology \& Evolution 2:86-93.

Trzcinski, M. K., D. S. Srivastava, B. Corbara, O. Dézerald, C. Leroy, J.-F. Carrias, A. Dejean, and R. Céréghino. 2016. The effects of food web structure on ecosystem function exceeds those of precipitation. Journal of Animal Ecology 85:1147-1160.

Tylianakis, J. M., E. Laliberté, A. Nielsen, and J. Bascompte. 2010. Conservation of species interaction networks. Biological Conservation 143:2270-2279.

Vannote, R. L., G. W. Minshall, K. W. Cummins, J. R. Sedell, and C. E. Cushing. 1980. The river continuum concept. Canadian Journal of Fisheries and Aquatic Sciences 37:130 137.

Woodward, G., and A. G. Hildrew. 2002. Food web structure in riverine landscapes. Freshwater Biology 47:777-798.

Woodward, G., et al. 2012. Continental-scale effects of nutrient pollution on stream ecosystem functioning. Science 336: $1438-1440$.

\section{SUPPORTING INFORMATION}

Additional supporting information may be found in the online version of this article at http://onlinelibrary.wiley.com/doi/ 10.1002/ecy.2633/suppinfo

\section{Data Avallability}

Data are available on Zenodo: https://doi.org/10.5281/zenodo.2533394 